\title{
Automatization and perceptual restructuring performance across the menstrual cycle
}

\author{
JOHN A. COOPER \\ Howard University, Washington, D. C. \\ JEROME H. BLUE \\ National Institute of Mental Health, Bethesda, Maryland \\ and \\ SHERMAN ROSS \\ Howard University, Washington, D.C.
}

\begin{abstract}
The cognitive performance of undergraduate psychology women $(n=49)$ and men $(n=48)$ was assessed using standardized automatization and perceptual restructuring measures. Women were classified into five groups based on the phase of the menstrual cycle they were experiencing at the time of testing. Results showed that the automatization performance of women who were expecting to menstruate in 11-15 days was better than that of males. The perceptual restructuring performance of all groups of women was about the same as that of men. The discussion focuses on a possible relationship between phases of the menstrual cycle and cognitive performance.
\end{abstract}

Phases of the menstrual cycle have rarely been assessed to determine relationships between automatization performance, which requires quick and accurate responses to well-learned tasks, and perceptual restructuring performance, which requires suppression of immediate responses in favor of forming and acting upon a well-organized percept of a complex stimulus. In general, automatization performance has been considered as one substantive area and perceptual restructuring performance as a separate area of study (Maccoby, 1966; Maccoby \& Jacklin, 1974), although it has recently been reported that automatization performance is related to perceptual restructuring performance (Broverman, Klaiber, \& Vogel, 1980). The menstrual cycle is related to hormonal changes, which may affect performance on cognitive tasks (Broverman, Klaiber, Kobayashi, \& Vogel, 1968). High levels of sex hormones, especially estrogen, are positively correlated with performance on automatization tasks, but are negatively correlated with performance on tasks that require complex perceptual restructuring (Broverman et al., 1968).

Recently, Broverman, Vogel, Klaiber, Majcher, Shea, and Paul (1981) reported differential responses

The authors thank J. Collins and Z. Elder for use of facilities at Howard University Hospital. They also appreciate the assistance of S. Thompson, P. Carr, and L. Short. Address all correspondence to: Sherman Ross, Howard University, Department of Psychology, Box 1097, Washington, D.C. 20059. The second author, J. H. Blue, contributed to this project prior to employment at the National Institute of Mental Health, Bethesda, Maryland. on cognitive tasks as a function of the menstrual cycle. College women were identified as ovulating by a change in daily body temperature. Participants were tested on Day 10 of their menstrual cycle and again on Day 20. Performance on three of four cognitive tasks (automatization and perceptual restructuring) changed significantly in participants tested 3 or fewer days before the thermal nadir, and on or after the thermal peak (Broverman et al., 1981). Englander-Golden, Willis, and Dienstbier (1977) reported that subgroups of menstruating women may lower the normative scores obtained by women as a whole, giving rise to observed sex differences on tests of cognitive abilities.

Sommer (1972) analyzed the performance of college women on two cognitive tasks across the menstrual cycle and found nonsignificant variations associated with phase of the menstrual cycle. Sommer's (1973) review of reports on menstrual effects on cognitive performance suggests that differences in methodology may account for the differences in findings. She reports that some studies used too few groups (e.g., premenstrual, menstrual, and midcycle), whereas others limited their study to women. Based on these and other findings (Blue, Cooper, \& Ross, 1980), we anticipated that, using standardized measures of automatization and perceptual restructuring, an assessment of the cognitive performance of women in several phases of the menstrual cycle would help to determine relationships between cognitive abilities and menstrual phase. The present study assesses automatization 
and perceptual restructuring performance; the performance of women in differing phases of the menstrual cycle was compared with the performance of men.

\section{METHOD}

\section{Subjects}

Undergraduate psychology students (49 women, mean age $=19$ years, and 48 men, mean age $=21$ years) attending Howard University, Washington, D.C., volunteered to participate. Ninetyone percent of the females reported that they menstruated regularly. About $13 \%$ of the sample of women were taking oral contraceptives. There was no significant difference in their performance on either the automatization or perceptual restructuring task, when compared with that of women who were not taking oral contraceptives. The performance scores in each group of women represent the performance of those who were and of those who were not taking oral contraceptives.

\section{Procedure}

Identification of menstrual phase. Women participants were asked the phase of the menstrual cycle they were experiencing and then were classified into one of five groups: (1) menstruating (2) expecting to menstruate in 1-5 days (3) expecting to menstruate in 6-10 days (4) expecting to menstruate in 11-15 days and (5) expecting to menstruate in 16 or more days. Group 6 consisted of a comparison group of men. All participants were requested to return for a second testing session approximately 10 days later. Table 1 shows the mean temperature for each group of women at both testing sessions.

Equivalent forms of cognitive tests were administered to all participants in a counterbalanced sequence, combining an auto- matization task with a perceptual restructuring task at Sessions 1 and 2 . The second session occurred approximately 10 days after the first. Women shifted groups; those in Group 1 at Session 1 might be in Group 5 at Session 2. All women participants were tested individually by a same-sex experimenter. In addition, women participants were asked a few questions about symptoms associated with their menstrual cycle (e.g., headaches, cramps, etc.).

Automatization tasks. Participants were required to name as fast as possible 10 lines of randomly ordered objects (e.g., tree, bee, and cup), 10 per line. The performance score was the amount of time taken to complete the task. Object naming was administered once, either in the first or the second testing session.

Both sets (backward and forward) of the WAIS-R Digit Span task were administered once, either in the first or the second session. The performance score was the number of correct responses.

Perceptual restructuring tasks. The complete set of 10 WAIS-R block designs (Wechsler Adult Intelligence ScaleRevised; Wechsler, 1974) was administered in either the first or the second session and scored according to standard procedures.

The complete WAIS-R object assembly subtest of four items was used. The task was administered in either the first or the second session and scored according to standard procedures.

\section{RESULTS}

\section{Automatization}

Table 2 shows the means and standard deviations for each group on the object-naming and digit-span tests. An analysis of variance showed no significant

Table 1

Mean Temperature for Each Group of Women in Various Phases of the Menstrual Cycle*

\begin{tabular}{|c|c|c|c|c|c|c|c|c|c|c|}
\hline \multirow[b]{3}{*}{ Sessions } & \multicolumn{10}{|c|}{ Groups } \\
\hline & \multicolumn{2}{|c|}{$1(n=11)$} & \multicolumn{2}{|c|}{$2(n=7)$} & \multicolumn{2}{|c|}{$3(n=12)$} & \multicolumn{2}{|c|}{$4(n=5)$} & \multicolumn{2}{|c|}{$5(n=14)$} \\
\hline & Mean & SD & Mean & SD & Mean & SD & Mean & SD & Mean & SD \\
\hline$T_{1}$ & 86.5 & 2.3 & 88.2 & .75 & 88.9 & 2.0 & 87.6 & 2.1 & 88.1 & 2.7 \\
\hline $\mathrm{T}_{2}$ & 89.2 & 4.1 & 88.2 & 2.4 & 88.5 & 3.2 & 88.0 & 2.4 & 89.1 & 1.2 \\
\hline
\end{tabular}

Note-The average temperature for each group of women is listed. Temperatures of men ( $n=48)$ were not measured. Standard deviations are in parenthesis. Group 1, menstruating; Group 2, expecting to menstruate in 1-5 days; Group 3, expecting to menstruate in 6-10 days; Group 4, expecting to menstruate in 11-15 days; Group 5, expecting to menstruate in 16 or more days. ${ }^{*}$ Measured by a Biotic wrist band (Bio-temp Products, Indianapolis)

Table 2

Differences in Means and Standard

Deviations in Performance on the Cognitive Tasks

\begin{tabular}{|c|c|c|c|c|c|c|c|c|c|c|c|c|}
\hline & \multicolumn{12}{|c|}{ Groups } \\
\hline & \multicolumn{2}{|c|}{1} & \multicolumn{2}{|c|}{2} & \multicolumn{2}{|c|}{3} & \multicolumn{2}{|c|}{4} & \multicolumn{2}{|c|}{5} & \multicolumn{2}{|c|}{6} \\
\hline & Mean & SD & Mean & SD & Mean & SD & Mean & SD & Mean & SD & Mean & SD \\
\hline & & \multicolumn{11}{|c|}{ Automatization } \\
\hline Object Naming* & 61.3 & 7.1 & 60.7 & 9.3 & 66.8 & 11.8 & 58.8 & 11.7 & 63.1 & 6.8 & 69.8 & 13.0 \\
\hline \multirow[t]{2}{*}{ Digit Span } & 17.6 & 2.6 & 15.1 & 3.7 & 15.6 & 3.7 & 17.8 & 1.9 & 17.0 & & & \\
\hline & \multicolumn{12}{|c|}{ Perceptual Restructuring } \\
\hline Block Design & 30.0 & 12.6 & 31.2 & 9.5 & 25.1 & 10.7 & 35.8 & 5.9 & 26.1 & 10.3 & 29.4 & 9.3 \\
\hline Object Assembly & 32.0 & 1.9 & 31.8 & 2.3 & 31.0 & 1.8 & 33.2 & 2.4 & 31.3 & 1.9 & 31.7 & 2.7 \\
\hline
\end{tabular}

Note-The scores listed by groups represent the mean score for Sessions 1 and 2. Group 1, menstruating; Group 2, expecting to menstruate in 1.5 days; Group 3, expecting to menstruate in 6-10 days; Group 4, expecting to menstruate in 11-15 days; Group 5, expecting to menstruate in 16 or more days; Group 6, men. $\quad{ }^{*} p<.05$. 
differences between the groups on the digit-span test (see Figures 1 and 2). A difference $[F(5,96)=$ $2.25, \mathrm{p}<.04$ ] was found among the groups on the object-naming test.

\section{Perceptual Restructuring}

Table 2 shows the means and standard deviations for each group on the block-design and objectassembly tests. There were nonsignificant differences between the groups on both these tests (see Figures 1 and 2).

A positive correlation was found between the performance of Group 1 in Sessions 1 and 2 on the object-assembly and the object-naming test $(r=.55$, $\mathrm{p}<.05)$ and on the digit-span and block-design test $(r=.74, p<.07)$. No other groups had high positive correlations on both the automatization and perceptual restructuring tests in both sessions. However, Group 6 (men) had a significant positive correlation $(r=.41, p<.01)$ between the automatization and perceptual restructuring tests in the second session, but a nonsignificant negative correlation $(r=-.15)$ between these tests in the first testing session.

\section{DISCUSSION}

The findings suggest that automatization performance may be facilitated by a particular phase of the menstrual cycle, but that perceptual restructuring performance may not. Support of the present findings might be obtained if hormonal assessments could be made throughout the menstrual cycles of women being tested on specific cognitive measures. A physiological assessment would further determine whether there was a relationship between phases of the menstrual cycle and automatization and perceptual restructuring performance.

The performance of women has been reported as being superior in automatization tests, and that of men as being superior in perceptual restructuring tests. This is possibly due to a greater potency of estrogen as an adrenergic stimulant (Broverman et al., 1980). We found that women and men performed similarly on perceptual restructuring tests, which supports some previous findings (Sommer, 1972, 1973) but contradicts others (Broverman et al., 1981; Englander-Golden et al., 1977).

Women who were menstruating performed well on automatization and perceptual restructuring tests, contradicting the notion that increases in sex hormone levels (e.g., during menses) affects patterning of cognitive abilities by improving automatization at the expense of the ability to engage in complex perceptual restructuring. The performance of men at the second session also contradicts this relationship, because males who performed well on the automatization test also performed well on the perceptual restructuring test. The men had a negative correlation between these opposing tasks in Session 2, providing support for Broverman et al.'s (1968) notion. Additional support for this notion arises from our finding that women who were expecting to menstruate in 11-15 days performed better than men on an automatization task.

There is a need to examine a larger group of women in different phases of the menstrual cycle, over a large period of time (e.g., months) and with some on oral contraceptives and others not in order to determine whether oral contraceptives can affect the results. In addition, our preliminary analyses of symptoms women experience during menses suggest that headaches, pain,
AUTOMATIZATION: Object Naining

PERCEPTUAL RESTRUCTURING: Block Design
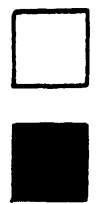
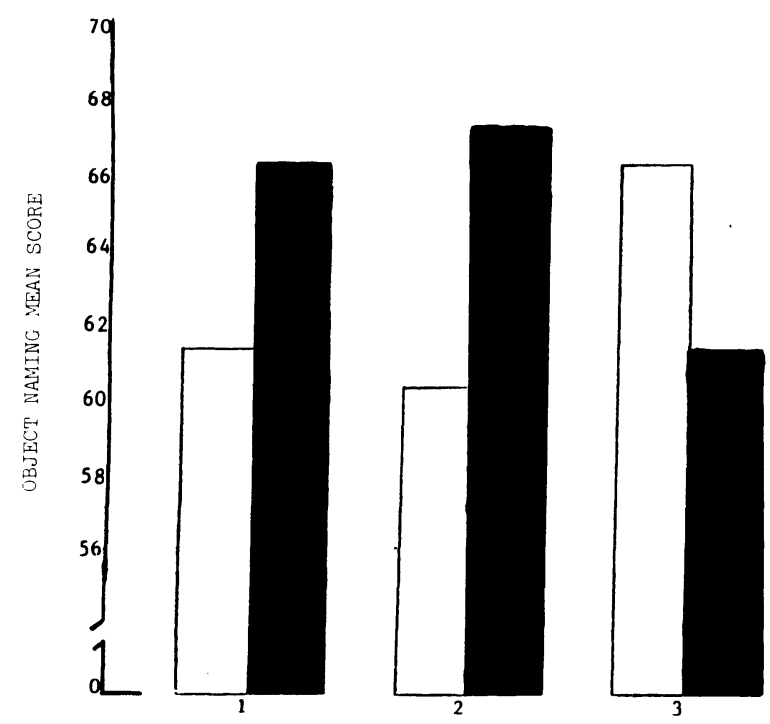

WOMEN
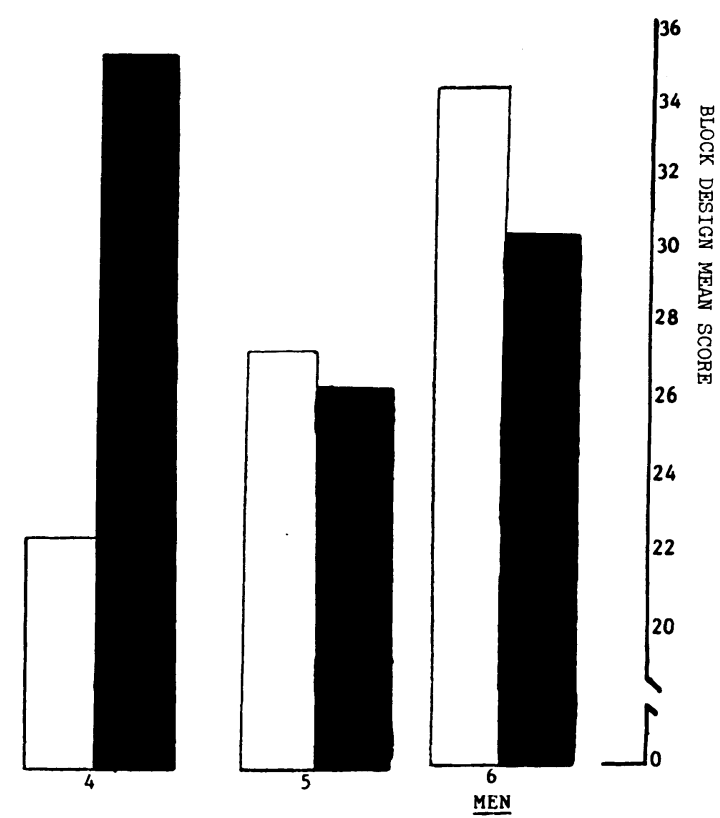

Figure 1. Object-naming and block-design performance of women and men. 


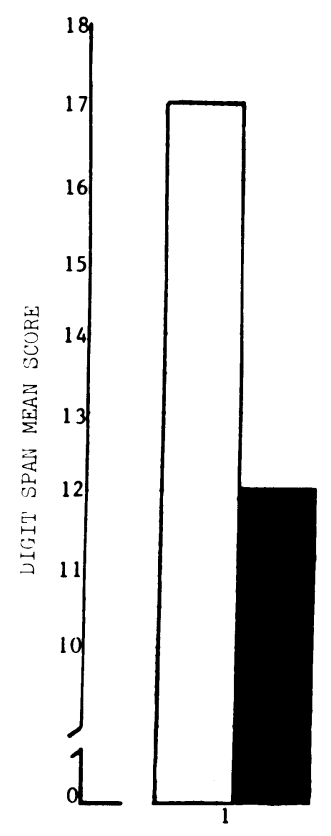

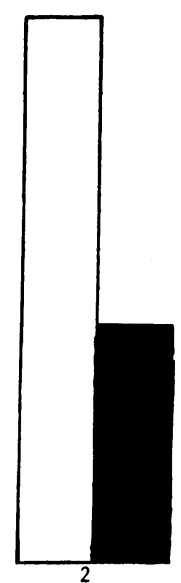

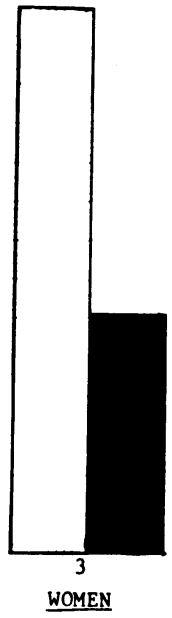

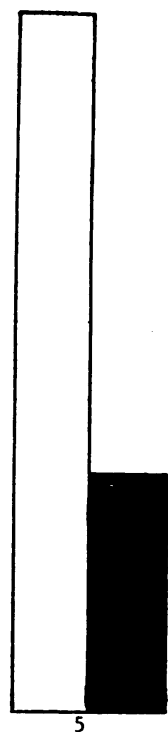

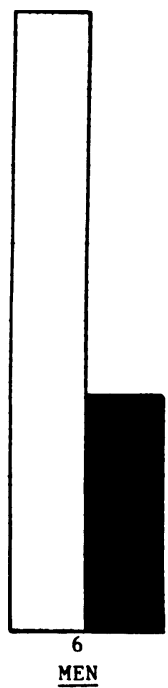

Figure 2. Digit-span and object-assembly performance of women and men.

etc., might be related to performance on cognitive tasks. Further research using standardized symptomology checklists is needed to establish whether there are relationships between menstrual symptoms and cognitive performance.

Women in different phases of the menstrual cycle performed similarly on the perceptual restructuring task, but not on the automatization task. Thus, it appears that certain phases of the menstrual cycle may affect automatization performance, but support for this notion would be provided if additional research, using larger groups of women who are assessed cognitively and hormonally, yielded similar results.

\section{REFERENCES}

Blue, J. H., Cooper, J. C., \& Ross, S. Field independence/ dependence, sex, and water levels. Bulletin of the Psychonomic Society, 1980, 6, 194-196.

Broverman, D. M., Klaiber, E. L., Kobayashi, Y., \& VogeL, W. Roles of activation and inhibition in sex differences in cognitive abilities. Psychological Review, 1968, 75, 23-50.

Broverman, D. M., Klaiber, E. L., \& Vogel, W. Gonadal hormones and cognitive functioning. In J. E. Parsons (Ed.),
The psychobiology of sex differences and sex roles. Washington: Hemisphere, 1980.

Broverman, D. M., Vogel, W., Klaiber, E. L., Majcher, D., Shea, D., \& Paul, V. Changes in cognitive tasks performance across the menstrual cycle. Journal of Comparative and Physiological Psychology, 1981, 95, 646-654.

Englande R-Golden, P., Willis, K. A., \& Dienstbier, R. A. Intellectual performance as a function of repression and menstrual cycle. Resources in Women's Educational Equity, 1977, 1.

Maccoвy, E. E. The development of sex differences. Stanford, Calif: Stanford University Press, 1966.

Maccoby, E. E., \& Jacklin, C. N. The psychology of sex differences. Stanford, Calif: Stanford University Press, 1974.

Sommer, B. Menstruation cycle changes and intellectual performance. Psychosomatic Medicine, 1972, 34, 263-269.

Sommer, B. The effect of menstruation on cognitive and perceptual-motor behavior: A review. Psychosomatic Medicine, 1973, 35, 515-534.

WechSLER, D. Manual for the Wechsler Intelligence Scale for Adults. New York: Psychological Corporation, 1974.

(Received for publication April 3, 1983.) 